\title{
O MAPEAMENTO DA PRODUÇÃO EDITORIAL ITALIANA TRADUZIDA NO BRASIL POR MEIO DA DESCRIÇÃ̃O BIBLIOGRÁFICA
}

\begin{abstract}
José Fernando Modesto da SiLVA*
RESUMO: Atualmente, devido ao grande desenvolvimento das comunicações, a presença da cultura e das artes italianas no Brasil está em fase de crescente intensificação e a quantidade de obras italianas que circulam no Brasil é cada vez maior. Assim, a proposta desta comunicação é apresentar a descrição bibliográfica aplicada na construção de uma base de dados bibliográficos, resultante de mapeamento editorial da literatura italiana traduzida no Brasil a partir de 1951. Dá-se destaque aos elementos descritivos utilizados, ajustados para esta finalidade com base também na necessidade dos pesquisadores envolvidos. Na descrição do projeto verifica-se a possibilidade de colaboração efetiva gerada entre as áreas de Biblioteconomia e de Letras. Também, evidencia-se a contribuição que um método tradicional como a catalogação pode ser aplicada para subsidiar a construção de uma base bibliográfica da produção editorial para fins científicos.

PALAVRAS-CHAVE: Catalogação; descrição bibliográfica; literatura italiana; projeto de pesquisa
\end{abstract}

ABSTRACT: Attualmente, dato il grande sviluppo delle comunicazioni, la presenza della cultura e delle arti italiane in Brasile è in fase di crescente aumento

* Universidade de São Paulo, São Paulo (Brasil) - fmodesto@usp.br

Processo n.2013/20971-0 Fundação de Amparo à Pesquisa do Estado de São Paulo (FAPESP)

DOI: http://dx.doi.org/10.11606/issn.2238-8281.v0i33p5-24 
e la quantità di opere italiane che circolano in Brasile è sempre maggiore. Con il presente testo si propone pertanto di presentare la descrizione bibliografica applicata alla costruzione di una base di dati bibliografici, che risulta dalla mappa editoriale della letteratura italiana tradotta in Brasile a partire dal 1951. Si è dato rilievo agli elementi descrittivi utilizzati, adattati a questo scopo, anche sulla base delle esigenze dei ricercatori coinvolti. Nella descrizione del progetto si verifica l'effettiva possibilità di collaborazione tra l'area di Biblioteconomia e quella di Lettere. Si evidenzia inoltre il contributo che un metodo tradizionale come quello della catalogazione può offrire, quando applicato per sussidiare la costruzione di una base bibliografica della produzione editoriale a scopi scientifici.

PAROLE CHIAVE: Catalogazione; descrizione bibliografica; letteratura italiana; progetto di ricerca.

ABSTRACT: Nowadays, due to the development of communications and presence of Italian culture and art, Brazil faces an increasing intensification phase where the amount of Italian works in circulation is growing. Thus, the purpose of this disclosure is to present the bibliographic description applied to build a resulting bibliographic database editorial mapping of the Italian literature translated in Brazil from 1951. This study emphasizes the descriptive elements used, adjusted for this purpose based also in need of the researchers involved. The description of the project allows an effective collaboration between the areas of Library Science and Letters. Also, it highlights the contribution of a traditional method as a dynamic way of cataloging in building a collection reference of editorial production for scientific purposes.

KEYWORDS: Cataloging; bibliographic description; Italian literature; research project. 


\section{Introdução}

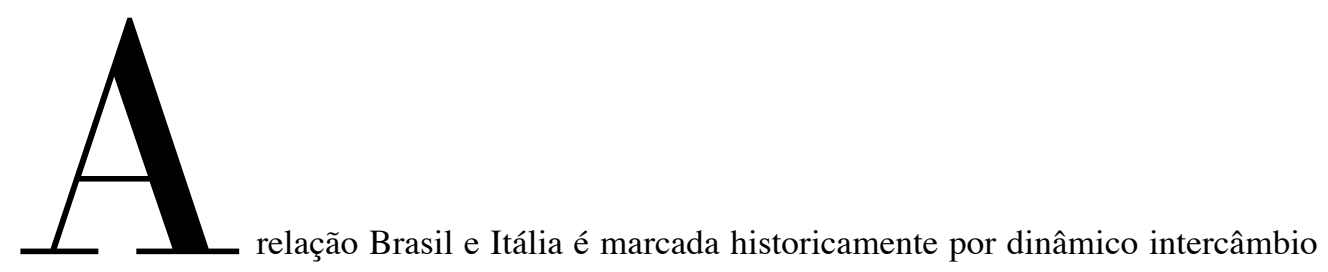

social, econômico e cultural. Atualmente, devido ao desenvolvimento das comunicações, "a presença da cultura e das artes italianas no Brasil está em fase de crescente intensificação e a quantidade de obras italianas - não apenas literária - que circula no Brasil é cada vez maior" (WATAGHIN, 2013, p. 20).

É um cenário que desperta real interesse em melhor identificar este legado das relações ítalobrasileiras e, em especial, da sua produção bibliográfica. Aspecto que tem sido manifestado por meio do trabalho sistematizado realizado pelo grupo de pesquisa "Literatura Italiana Traduzida". Trata-se de ação colaborativa entre pesquisadores da Universidade Federal de Santa Catarina UFSC e da Universidade de São Paulo - USP com o objetivo de mapear a história da circulação da literatura italiana traduzida no Brasil, no século XX, e na primeira década do século XXI.

Neste sentido, desenvolve-se investigação que busca apontar para obras e seus autores, de maneira a enfatizar momentos que realçam as relações do ambiente em que surgiram e o ambiente em que são acolhidos. Destaca-se a ideia na qual o meio privilegiado com que um país acolhe uma obra é a tradução. 
Os primeiros questionamentos surgidos aos pesquisadores se relacionaram com o encaminhamento do conjunto de livros coletados, basicamente sobre como pensar os procedimentos de seu registro, além de pensar o arquivo contemplativo das relações literárias entre Brasil e Itália.

Em termos metodológicos, a proposta desta comunicação é apresentar, comentar e descrever os procedimentos adotados com a aplicação de procedimentos descritivos para a construção de uma base de dados bibliográfica orientada ao mapeamento da produção editorial da literatura italiana produzida no Brasil a partir de 1951. Dá-se destaque aos elementos descritivos utilizados e ajustados para esta finalidade e, também, às necessidades dos pesquisadores envolvidos com o projeto.

Portanto, o objetivo da comunicação é destacar como aspectos pertinentes à descrição bibliográfica tradicional à área da Biblioteconomia podem subsidiar projetos da área das Letras, em especial, Letras Italianas. Com ajustes aos princípios de aplicação da representação descritiva geraram resultados colaborativos e significativos em termos de comunicação científica interdisciplinar.

Neste sentido, apresenta-se uma síntese do projeto realizado, seus objetivos principais e propostas de desenvolvimento. Na sequência, contextualizam-se alguns dos elementos da descrição bibliográfica utilizada para facilitar a integração dos procedimentos descritivos aplicados às necessidades do projeto de mapeamento da produção literária. Abordam-se os resultados alcançados com a investigação, e elaboram-se considerações finais sobre o projeto e o aproveitamento dos recursos descritivos aplicados.

\section{Dicionário da Literatura Italiana Traduzida: o Projeto}

O Grupo de pesquisa "Dicionário de Literatura Italiana Traduzida" surgiu do trabalho colaborativo entre pesquisadores da Universidade de São Paulo - USP e da Universidade Federal de Santa Catarina - UFSC. Nasce em torno do projeto "A literatura italiana traduzida no sistema literário nacional” financiado pelo edital n. 02/2010 - MCT/CNPq/MEC/CAPES.

Dentre os resultados alcançados destacam-se a publicação: "Literatura Italiana Traduzida no Brasil: 1900-1950", e a base de dados: "Dicionário bibliográfico eletrônico da literatura italiana traduzida" (www.dlit.ufsc.br). O projeto iniciado em 2010 foi finalizado em 2012 (PETERLE; SANTURBANO; WATAGHIN, 2013). 
Em consequência desta iniciativa emerge a proposta de explorar o panorama da literatura traduzida no Brasil a partir de 1951 até a década atual do século XXI, de forma a indicar obras, autores, momentos, episódios em seu contexto de partida mas, sobretudo, de chegada, ou seja, em suas relações com o ambiente em que surgiram e sobretudo com o ambiente que os acolhe.

$\mathrm{Na}$ concepção do projeto reside a ideia de que o meio privilegiado com que um país dá as boas-vindas a uma obra é a tradução. Assim, desenvolver reflexões sobre as traduções em seu contexto de chegada significa também refletir sobre este mesmo contexto, isto é, sobre o sistema literário nacional (WATAGHIN, 2013).

Entende-se que as literaturas traduzidas, concebidas como sistemas literários especiais dentro dos "polissistemas" constituídos pelas literaturas nacionais sofrem condicionamentos peculiares de acordo com os diversos momentos atravessados pelos países que as recebem (EVEN-ZOHAR, 2007, p.229).

Neste sentido, os textos traduzidos são lidos, comentados, reescritos e se entrelaçam nessa intrincada trama que é o universo literário. Em síntese, essa relação entre um dado sistema literário e a literatura traduzida configura um sistema que é complexo e dinâmico. A literatura traduzida vista por esse ângulo é concebida como um co-sistema partícipe e ativo de um todo maior, denominado polissistema (WATAGHIN, 2013).

$\mathrm{Na}$ tentativa de identificar as forças envolvidas num polissistema, Even-Zohar (2007, p.230) define três casos principais. O primeiro contempla as literaturas ditas jovens, isto é, não ainda consolidadas e, por isso, mais propensas a receber aquilo que vem de fora. O segundo é o dos sistemas literários ditos "periféricos" ou "fracos", caso um pouco semelhante ao primeiro, mas no âmbito de uma literatura que já pode estar consolidada; mas o sistema, por ser "periférico", parece ser também sensível a produções provenientes de outros sistemas. E, finalmente, o terceiro caso se dá quando há pontos de mudanças, crises ou vazios num sistema literário.

Se a tradução é uma reescrita, como aponta Lefevere (2007), têm-se o estabelecimento de relação sistêmica que pode desencadear uma série de outros textos (resenhas, artigos críticos, etc.). A própria tradução é fundamental nas relações entre os sistemas literários e é essencial para o diálogo que pode ser iniciado entre eles a partir da publicação e circulação do texto traduzido num novo ambiente.

Essa relação, que aos poucos vai sendo estabelecida e construída entre o que é lido, traduzido e (re)criado e escrito, pode ser vista a partir de vários ângulos, mas aquele que interessa para as relações entre os Estudos da Tradução e a Literatura Comparada é o das interlocuções entre 
sistemas literários diferentes e até distantes (WATAGHIN, 2013).

Como objetivo principal do projeto comentado encontra-se a promoção de continuidade da base de dados "Dicionário Bibliográfico da Literatura Italiana", no que se refere ao aspecto descritivo das obras arroladas para a pesquisa, bem como o seu uso como fonte de consulta por estudantes e pesquisadores da área de letras italianas.

Em relação aos objetivos específicos do Projeto, relaciona-se: a) levantamento dos títulos de literatura italiana traduzidos no Brasil, de 1951 às primeiras décadas do século XXI; b) formação de um quadro da presença e da importância de autores e obras italianos no panorama brasileiro no inteiro período (séculos XX e XXI); c) formação de um quadro da presença e importância das várias editoras ativas no mercado da literatura italiana traduzida; d) observação e análise, na área da recepção brasileira da literatura italiana a partir de 1900, dos movimentos das ideias e das transformações no ambiente de chegada.

Saliente-se que o Projeto sob o título "Mapeamento e Dicionário da Literatura Italiana Traduzida: Projeto Integrado" teve financiamento da FAPESP (Fundação de Amparo à Pesquisa do Estado de São Paulo), para o período de 2014 - 2016 (processo 20971-0). O parecer final sobre o relatório de conclusão apresentado destacou a execução de acordo com as previsões e os ótimos resultados alcançados. A investigação envolveu docentes/pesquisadores, estudantes de letras (graduação e pós-graduação), tradutores de italiano, docente/pesquisador de biblioteconomia. A finalização do projeto resultou em site disponível para consulta dos livros mapeados (http://www.usp.br/dlit/), além do inventário de estudos e artigos resultantes da atividade realizada e que exemplificam sua importância. Ademais, o material bibliográfico reunido se constituiu em um arquivo precioso de informações sobre obras que mudam o caráter do campo de estudos das traduções literárias entre Brasil e Itália, oferecendo novos percursos para futuras pesquisas.

\section{Interação das Áreas de Letras e de Biblioteconomia}

Destaque significativo a mencionar foi a parceria estabelecida entre as áreas de Letras e de Biblioteconomia para o desenvolvimento do Projeto. A cooperação entre especialistas decorreu de um desafio do tipo estritamente metodológico, ou seja, a necessidade de avaliar e adequar os critérios de descrição em relação ao tipo de informação bibliográfica que deveria ser fornecida para o mapeamento da literatura italiana traduzida no Brasil. A definição das fronteiras entre 
"gêneros" - em relação à oportunidade de coletar e inserir, ou não, certas obras e, ainda, questões sobre a descrição de obras muitas vezes reeditadas, com pequenas variações editoriais.

Além disso, o grupo de pesquisa se deparou com o desafio tecnológico, ao buscar produzir uma base de dados de certa complexidade, na medida em que o número de obras a serem cadastradas era muito maior em relação ao levantamento realizado no projeto anterior relativo ao período de 1900 a 1950.

Para a nova fase do Projeto houve a colaboração da área de Biblioteconomia (da Universidade de São Paulo) com um docente/pesquisador responsável pela revisão da estrutura descritiva dos livros coletados e ajustada às necessidades do projeto e da equipe de especialistas em letras italianas.

Acrescente-se que outros desafios tecnológicos, diretamente ligados à área de informática, foram enfrentados com o apoio da Superintendência de Tecnologia da Informação da USP, e da Seção Técnica de Informática da FFLCH/USP (Faculdade de Filosofia, Letras e Ciências Humanas) no fornecimento de infraestrutura computacional para instalação da arquitetura do site e banco de dados.

Ademais, o orçamento para a realização do projeto previu a prestação de serviços de um programador para a implementação do site e do banco de dados para construção da base de dados bibliográfica, no ambiente denominado: Dicionário da Literatura Italiana Traduzida a partir de 1951.

Ressalte-se a utilização na concepção do ambiente o software Wordpress. Um sistema de gerenciamento de conteúdo para a web, desenvolvido em linguagem PHP (acrônimo recursivo para Hypertext Preprocessor, originalmente Personal Home Page) e contando com o banco de dados MySQL um sistema gratuito e distribuído sob licença GNU (General Public Licence). A escolha do programa decorreu da sua flexibilidade de aplicação (possibilidade de desenvolver sites de comércio eletrônico, revistas, jornais, diretórios e outros conteúdos), devido a sua capacidade de extensão por meio de aplicativos e modelos pré-formatados além de recursos em linguagens de marcação aderentes aos padrões W3C (World Wide Web Consortium) e por influência do programador contratado.

\section{Pressupostos da representação descritiva}

Como parte do tratamento da informação, a catalogação contempla o processo da representação descritiva dos materiais bibliográficos. Envolve em suas características e finalidades a elaboração de registros que permitam a recuperação da informação bibliográfica. Estes registros devem ser 
estruturados segundo padrões apoiados em princípios e normas internacionais.

Ramos Fajardo (2001) comenta que a descrição bibliográfica é concebida por meio de um conjunto de dados que permitem identificar o documento a fim de proporcionar uma representação do mesmo, que o descreva de forma única, sem ambiguidades e que permita sua identificação e localização no catálogo.

Mey e Silveira (2009) acrescentam que a catalogação é composta por conjunto de informações que também simbolizam um registro do conhecimento. Não se trata de trabalho mecânico, ao contrário, envolve o levantamento das características dos registros e a cognição dos usuários, que se define como:

O estudo, preparação e organização de mensagens, com base em registros do conhecimento, reais ou ciberespaciais, existentes ou passíveis de inclusão em um ou vários acervos, de forma a permitir a interseção entre as mensagens contidas nestes registros e as mensagens internas dos usuários (Mey; Silveira, 2009, p.7).

A essência do processo de descrição bibliográfica fundamenta-se no estabelecimento de relacionamentos possíveis entre os registros do conhecimento, que geram alternativas de escolha e análise para o usuário.

Entretanto, no que se refere à aplicação descritiva, o Projeto não está restrito às estruturas biblioteconômicas. Assim, tornou-se importante ajustar aspectos dos processos catalográficos sem descaracterizar os objetivos e as necessidades de análise definidos pelo grupo de pesquisa. A questão inicial foi adequar um modelo descritivo para determinar uma estrutura de dados e que viabilizasse a consulta dos registros e sua identificação com o material físico levantado e comprado. Importa observar que o Projeto referenciou apenas obras literárias traduzidas, localizadas em bibliotecas, editoras, livrarias e sebos. Também mapeou material em posse de especialistas da área (notadamente participantes do grupo de pesquisa) no Brasil. As obras encontradas em editoras, livrarias e sebos foram compradas e, ao final do projeto, foram doadas à Biblioteca da FFLCH/USP, conforme norma da agência financiadora.

\section{Recursos descritivos aplicados no dicionário bibliográfico}

Como referência de orientação para a elaboração e consistência da estrutura da base de dados do Dicionário da Literatura Italiana Traduzida no Brasil, buscou-se consonância com 
algumas das regras preconizadas pela AACR2r (Código de Catalogação Anglo-Americano, segunda edição revisada), que é uma norma para a descrição bibliográfica. Notadamente se utilizou instruções do capítulo 1, relativas às regras gerais de descrição para todos os tipos de materiais, e do capítulo 2, relativas aos livros, folhetos e folhas impressas. Da parte II do AACR2r utilizou-se como parâmetros regras do capítulo 21 para escolha dos pontos de acesso, e o capítulo 22, referente aos cabeçalhos para pessoas (CÓDIGO, 2004).

O instrumento descritivo foi importante para instruir e subsidiar deliberações para a estrutura da base bibliográfica (que não é um catálogo bibliográfico explícito) e outras questões necessárias à descrição e especificadas pelo Coordenadores e demais membros da equipe, além de apoiar no arbitramento de outras questões surgidas. Basicamente, o instrumento normativo ofereceu subsídios para identificar a estrutura de dados e incluir elementos como:

- Título principal;

- Outras informações sobre o título;

- Título original;

- Indicação de responsabilidade (referente às pessoas responsáveis por seu conteúdo intelectual ou artístico, entidades das quais emana o conteúdo, ou às pessoas responsáveis pela execução ou contribuição na obra);

- Edição (exemplares produzidos basicamente da mesma matriz e publicado pela mesma entidade publicadora);

- Informações da Publicação (lugar da publicação, nome do editor, data de publicação);

- Descrição física (no que se refere à extensão e dimensão do livro, basicamente número de página e tamanho em centímetros); e

- Notas (informações descritivas úteis para complementar a descrição do item, redefinida como Observações Gerais, por conflito terminológico de área). 
Estes elementos fixados pela norma se constituíram em um conjunto mínimo de informações para a composição dos registros bibliográficos. Foram acompanhados da respectiva explicitação do seu significado e os procedimentos de sua aplicação.

A partir da discussão entre os membros da equipe, definiu-se uma estrutura final para a descrição e registro dos livros coletados. Para essa finalidade, foi organizado um formulário de coleta (impresso e/ou digital) a ser preenchido no trabalho de campo, acompanhado de instruções básicas de preenchimento. Observa-se que a finalização do formulário necessitou de várias reuniões do grupo. Fato ocorrido pela falta, na equipe, de bolsistas de biblioteconomia (não houve interessados), as vagas destinadas foram preenchidas por bolsistas de letras italianas. $\mathrm{O}$ quadro 1 apresenta a estrutura definida e a síntese das orientações explicitadas para o registro descritivo dos dados.

Quadro 01 - Indicação dos Elementos Descritivos das Obras Traduzidas

\begin{tabular}{|c|c|}
\hline Elementos & Instruções Aplicadas \\
\hline Autor & $\begin{array}{l}\text { Informar o SOBRENOME, Nome do(s) autor(es). Observar a forma com } \\
\text { que aparecem na página de rosto do livro. Anotar nas Observações Gerais as } \\
\text { diferenças encontradas com a Capa. }\end{array}$ \\
\hline Título principal & $\begin{array}{l}\text { Título do livro traduzido. Transcreva o título exatamente no que respeita } \\
\text { à redação, ordem e grafia. Anotar nas Observações Gerais as diferenças } \\
\text { encontradas com a Capa. }\end{array}$ \\
\hline Ano - Tradução & Data de publicação ou copyright do livro traduzido. \\
\hline Título original & $\begin{array}{l}\text { Título do livro em italiano. Transcreva o título exatamente no que respeita à } \\
\text { redação, ordem e grafia, mas não necessariamente quanto à pontuação e ao uso } \\
\text { de maiúscula. Não transcreva palavras que servem como uma introdução e } \\
\text { não se destinam a fazer parte do título. Inclua tais ocorrências nas Observações } \\
\text { Gerais. }\end{array}$ \\
\hline Ano - Original & Data da publicação ou copyright da obra original na Itália, se houver. \\
\hline Edição - número & $\begin{array}{l}\text { Indicar a edição, se houver. Se há ou não indicação de edição, considere a } \\
\text { presença de palavras como edição, tiragem ou versão como evidências. }\end{array}$ \\
\hline
\end{tabular}




\begin{tabular}{|c|c|}
\hline Elementos & Instruções Aplicadas \\
\hline Cidade/lugar & $\begin{array}{l}\text { Indicar cidade e estado ou lugar da publicação. Por exemplo: São Paulo, SP ou } \\
\text { Cabrobó, CE. Se não há referência colocar [sine loco]. }\end{array}$ \\
\hline $\begin{array}{l}\text { Editor/ } \\
\text { Distribuidor/ } \\
\text { Impressor }\end{array}$ & $\begin{array}{l}\text { Indicar o nome do editor ou distribuidor etc. Se o nome do editor ou distribuidor } \\
\text { etc. for desconhecido, registre: [sine nomine]. }\end{array}$ \\
\hline Páginas/volume & $\begin{array}{l}\text { Indicar o número da última página com texto do conteúdo. Se forem vários } \\
\text { volumes, indicar separadamente o número de páginas de cada volume. Exemplo: } \\
\text { v. } 1,224 \text { p. }\end{array}$ \\
\hline Dimensões & $\begin{array}{l}\text { Indicar a altura e largura com uma casa decimal e colocar } \mathrm{cm} \text { no final. Por } \\
\text { exemplo: } 21,0 \times 14,0 \mathrm{~cm} .\end{array}$ \\
\hline Tradutor & $\begin{array}{l}\text { Informar o SOBRENOME, Nome do(s) tradutor(es). Observar a forma com que } \\
\text { aparecem na página de rosto ou no verso desta página. }\end{array}$ \\
\hline Organizador & $\begin{array}{l}\text { Informar o SOBRENOME, Nome do(s) organizador(es). Observar a forma } \\
\text { com que aparecem na página de rosto ou no verso desta página. Anotar nas } \\
\text { Observações Gerais as diferenças encontradas com a Capa. }\end{array}$ \\
\hline ISBN & Indicar o número do ISBN (se houver). \\
\hline $\begin{array}{l}\text { Antologia/ } \\
\text { Coletânea }\end{array}$ & Indicar o título da Antologia ou Coletânea no qual se inclui o texto traduzido. \\
\hline $\begin{array}{l}\text { (Indicar o Autor e } \\
\text { o Título) } \\
\text { Prefácio; Posfácio; } \\
\text { Introdução; } \\
\text { Apresentação; } \\
\text { Paratexto }\end{array}$ & $\begin{array}{l}\text { Informar o SOBRENOME, Nome do responsável ou responsáveis, e o Título (se } \\
\text { houver) das categorias indicadas. Anotar nas Observações Gerais as diferenças } \\
\text { encontradas com a Capa. }\end{array}$ \\
\hline Ilustração & $\begin{array}{l}\text { Informar SOBRENOME, Nome do(s) ilustrador (es). Anotar nas Observações } \\
\text { Gerais as diferenças encontradas com a Capa. }\end{array}$ \\
\hline Orelha & $\begin{array}{l}\text { Informar SOBRENOME, Nome do responsável (se houver). Anotar nas } \\
\text { Observações Gerais as diferenças encontradas. }\end{array}$ \\
\hline Capa & $\begin{array}{l}\text { Elaborar breve descrição da capa, principalmente se houver imagem de } \\
\text { ilustrador/pintor/desenhista conhecidos. }\end{array}$ \\
\hline Notas & Indicar se as notas são do autor, do tradutor, do organizador ou do editor. \\
\hline
\end{tabular}




\begin{tabular}{|l|l|}
\hline Elementos & Instruções Aplicadas \\
\hline $\begin{array}{l}\text { Localização } \\
\text { da Entidade } \\
\text { Responsável pela } \\
\text { guarda do livro }\end{array}$ & $\begin{array}{l}\text { Indicar a localização conforme lista de bibliotecas consultadas. Se o livro for de } \\
\text { particular, indicar o nome do proprietário. Se o livro for comprado pelo Projeto, } \\
\text { indicar DLIT/USP. }\end{array}$ \\
\hline $\begin{array}{l}\text { Observações } \\
\text { Gerais }\end{array}$ & $\begin{array}{l}\text { Informações complementares sobre o livro descrito e diferenças encontradas } \\
\text { entre a página de rosto e a capa do livro. }\end{array}$ \\
\hline
\end{tabular}

As orientações agregadas ao formulário alertavam para o registro de dados contidos exclusivamente nos livros analisados. Os campos delineados deveriam ficar em branco na ausência dos dados correspondentes. Junto à coleta dos dados, a imagem da capa do livro deveria ser obtida por meio de foto tirada com celular ou tablet.

Com relação ao elemento "Autor”, embora não se tenha adotado um controle rígido de autoridade, foram acrescidos ao mesmo, quando possível, dados bibliográficos do ano de nascimento e morte. No caso de Pseudônimo, o mesmo foi mantido como identificação de autoria, sem remissão para o nome conhecido. Apesar da regra 22.2B1 instruir que as obras de uma pessoa apareçam sob um único pseudônimo, optar pelo mesmo. E se o nome verdadeiro for conhecido fazer remissiva ao nome verdadeiro (CÓDIGO, 2004), apenas a primeira parte da instrução foi seguida. A deliberação foi adotada pela equipe sob a alegação de ser uma informação clara e conhecida aos especialistas em letras italianas, dispensando necessidade de remissiva ao nome conhecido. Da mesma forma a identificação do nome do Tradutor foi considerado tão importante quanto o nome do autor, até por atender as linhas de estudos relacionados aos processos linguísticos adotados na tradução. Também, a regra citada foi aplicada da mesma maneira. Aliás, para todas as pessoas identificadas em outras funções coletadas na descrição, adotou-se o procedimento para caso de pseudônimo. O mesmo foi observado com a regra 22.2B3 para autores contemporâneos, adotando mais de um pseudônimo ou nome verdadeiro, optando-se por manter o nome utilizado na obra descrita.

Pela necessidade manifesta dos pesquisadores, foi incluída a identificação de autor e título (quando houvesse) para os elementos: Prefácio, Posfácio, Introdução, Apresentação, Paratexto, além da identificação de Organizador e Ilustrador e do responsável pela "Orelha” do livro. No caso destes dados específicos, a ênfase do destaque decorre de serem, muitas vezes, escritores e tradutores ou estudiosos reconhecidos na área das Letras Italianas, no âmbito brasileiro e internacional. 
Para melhor facilitar a citação de outros casos vinculados aos nomes de autores, tradutores e demais responsáveis envolvidos na produção da obra descrita, adotaram-se as seguintes regras da parte II do AACR2r referente ao capítulo 22 (cabeçalhos para nome de pessoas):

- 22.2A: para nomes predominantes, no caso de ocorrência de pessoas conhecidas por mais de um nome ou a forma do nome mais frequente nas obras da pessoa, adotou-se a recomendação da forma pela qual é mais conhecida, segundo aval dos especialistas da equipe.

- 22.2C: instrução para mudança de nome com escolha do nome ou a forma mais recente, a não ser que haja razão para persistir uma forma anterior ao nome como mais conhecida. Na pouca ocorrência identificada foi mantida a forma anterior por deliberação da equipe, pelo fato da pessoa ser mais conhecida na área.

- 22.3: escolha entre formas diferentes de um mesmo nome. Observaram-se as instruções das regras sob o tópico, acompanhadas das instruções contidas nas regras 22.5 referentes à entrada pelo sobrenome. Foram instruções importantes diante de uma situação editorial encontrada, ou seja, nomes de autores italianos grafados ora em português, ora em italiano. Optou-se por seguir grafia original do nome em italiano, o mesmo valendo para outras responsabilidades listadas, de origem italiana.

- 22.8: entrada pelo prenome etc. (22.8A1) e 22.13: entrada para santos. Duas instruções observadas para definir a entrada para uma obra literária identificada como sendo de São Francisco de Assis. Incluída após muita discussão.

No que se refere aos nomes de pessoas, não se procedeu a um controle de autoridade mais rígido, com adoção de referências cruzadas para forma adotada, variações do nome e etc., por decisão da maioria do grupo, subsidiada pela seguinte exposição de motivos: 
- prazo de finalização do projeto;

- ausência de bolsistas de biblioteconomia;

- indisponibilidade do suporte de programação;

- o projeto ser orientado para especialistas em letras italianas e

- o principal, o material bibliográfico comprado seria repassado para a biblioteca da FFLCH/USP.

Quanto ao título principal relativo aos livros descritos foram observadas as instruções emanadas nas regras 21.2 relativas às mudanças no título principal. Entretanto, não houve ocorrências significativas ou quantitativas, mas as ocorrências identificadas foram registradas nas Observações Gerais conforme instrução 1.7B4, relativa a área das notas, na AACR2. Observadas também as instruções emanadas no Capítulo 2 (2.1B - título principal) e o correspondente no Capítulo 1 (1.1B - título principal).

O título original é desdobrado da regra 2.7B2: língua do item e/ou tradução ou adaptação, ajustado como um campo para inclusão do título original da obra traduzida.

A área da publicação e da distribuição dos capítulos 1 e 2, subsidiaram as instruções para os campos desdobrados em: cidade/lugar (2.4C/1.4C); editor/distribuidor/impressor (2.4D/1.4D) e ano - tradução (2.4F/1.4F). O ano - original, inicialmente criado, mostrou-se inadequado, pois poucas publicações apresentavam os dados requeridos; não houve regras para subsidiar sua criação. Da mesma forma, não houve regra para subsidiar a criação do elemento "Capa". Aliás, esse elemento se mostrou insipiente para a descrição, embora fosse especificação acordada pela equipe.

Os elementos: Páginas/volume (2.5: número de volumes e/ou paginação) e Dimensões (2.5D: dimensões) correspondem à área da descrição física da AACR2 . A adaptação feita refere-se, no caso Página/volume, registrar apenas a paginação (2.5B2) e volume (2.5B16). As Dimensões, adaptadas da regra $2.5 \mathrm{D}$, para informar apenas a largura e a altura em centímetros.

A informação do ISBN está subsidiada pela regra 2.8B para o Número Internacional Normalizado do Livro, com foco apenas no seu registro. 
O elemento "Coletâneas/Antologias" foi adotado para resolver a situação de textos italianos traduzidos, mas incluídos em publicações reunindo autores diversos (não só italianos), uma maneira de realizar a descrição de parte do todo. A dificuldade de sua aplicação decorreu do fato de ser clara aos bibliotecários nas atividades de catalogação, mas dificultosa para leigos no conceito. O elemento "Nota" refere-se a uma necessidade específica dos pesquisadores em relação à publicação traduzida. O termo inclusive é adotado em estudos literários. Para não conflitar com as nomenclaturas adotadas, criou-se o elemento "Observações Gerais" para indicar outras informações complementares identificadas em relação aos aspectos físicos ou de conteúdo das publicações conforme função da área de notas 2.7 da AACR2.

Os problemas surgidos, relacionados à descrição, eram discutidos entre a equipe, com explicação pelo responsável da área de Biblioteconomia. As deliberações eram registradas em documento das reuniões.

Enfim, os elementos prescritos para descrição dos livros em sua maioria, estão previstos na AACR2. Para desenvolvimento do Projeto desdobraram-se elementos em campos específicos, dados para facilitar a compreensão e coleta realizada pelos membros da equipe.

Importante ressaltar que os membros da equipe foram orientados na coleta dos dados bibliográficos por meio do preenchimento do formulário. Porém, não foram capacitados em conceitos e fundamentos da catalogação. Na oportunidade, foram apresentados à missão da biblioteca universitária, à função do catálogo bibliográfico e ao trabalho do bibliotecário.

Aspectos que muitos desconheciam. Entretanto, a mencionada ausência de bolsista em biblioteconomia restringiu a maior contribuição da área ao projeto desenvolvido.

\section{Resultados do Projeto Literatura Italiana Traduzida no Brasil}

Os resultados esperados e alcançados no Projeto estão materializados nas publicações geradas, decorrentes do empenho dos membros participantes, também na construção e operacionalização do site e da base de dados bibliográfica que inventariam as atividades realizadas. No projeto inicial (1900 a 1950), elaborou-se uma listagem com cerca de 1200 registros de livros. No período de 1951 às primeiras décadas do século XXI, os registros levantados se multiplicaram por três, apenas no que se refere à literatura italiana. Na figura 1, apresenta-se a interface de consulta da base disponibilizada online. 
Figura 1 - Interface de Consulta do Dicionário Bibliográfico de Literatura Italiana

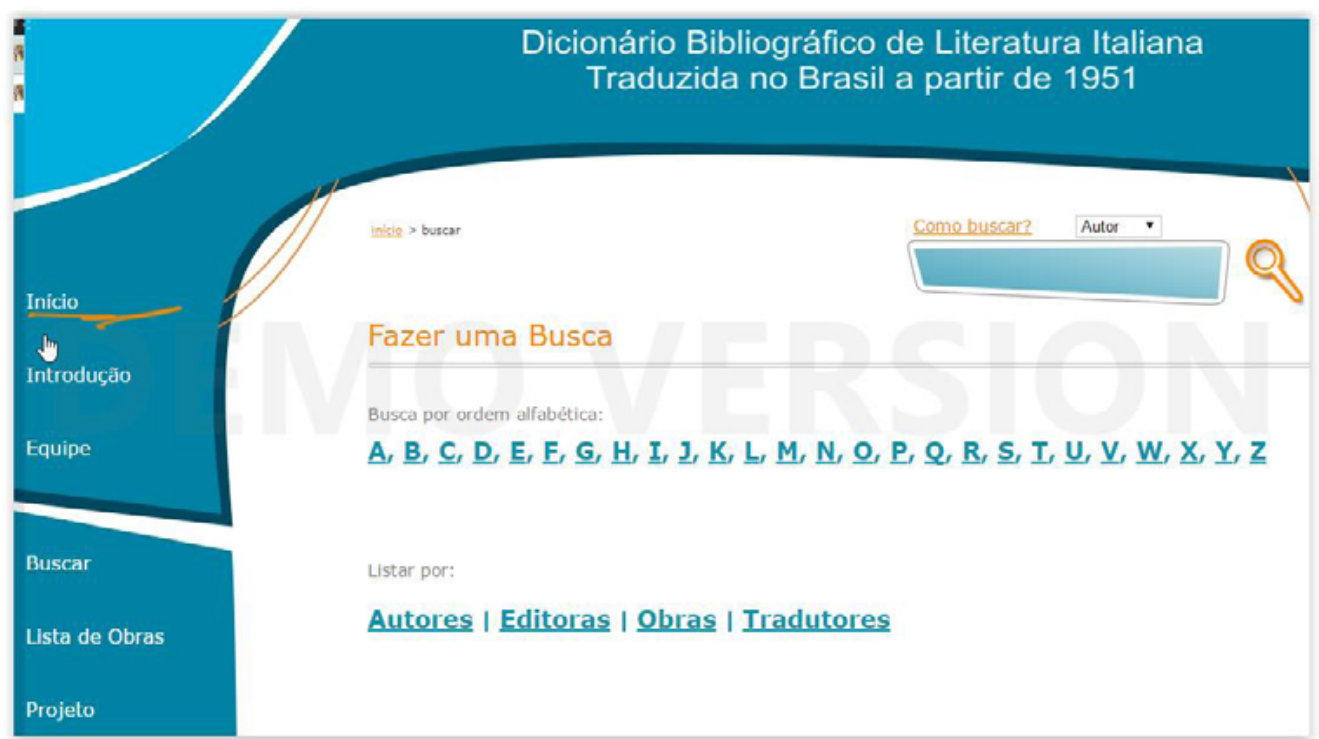

Fonte: Elaborado pelos autores, 2016.

Recurso disponível em: http://www.usp.br/dlit/dicionario/busca.php.

Observa-se na figura que a consulta pode ser realizada por categorias: autores, editoras, obras (título original e traduzidos) e tradutores. A busca alfabética abre a consulta por listas ordenadas das categorias citadas.

Na figura 2 é apresentado um modelo de registro bibliográfico, estruturado sob as especificações adotadas, e que resulta da consulta realizada na interface da figura 01 . 
Figura 2 - Apresentação do Registro na Base de Dados Bibliográfica

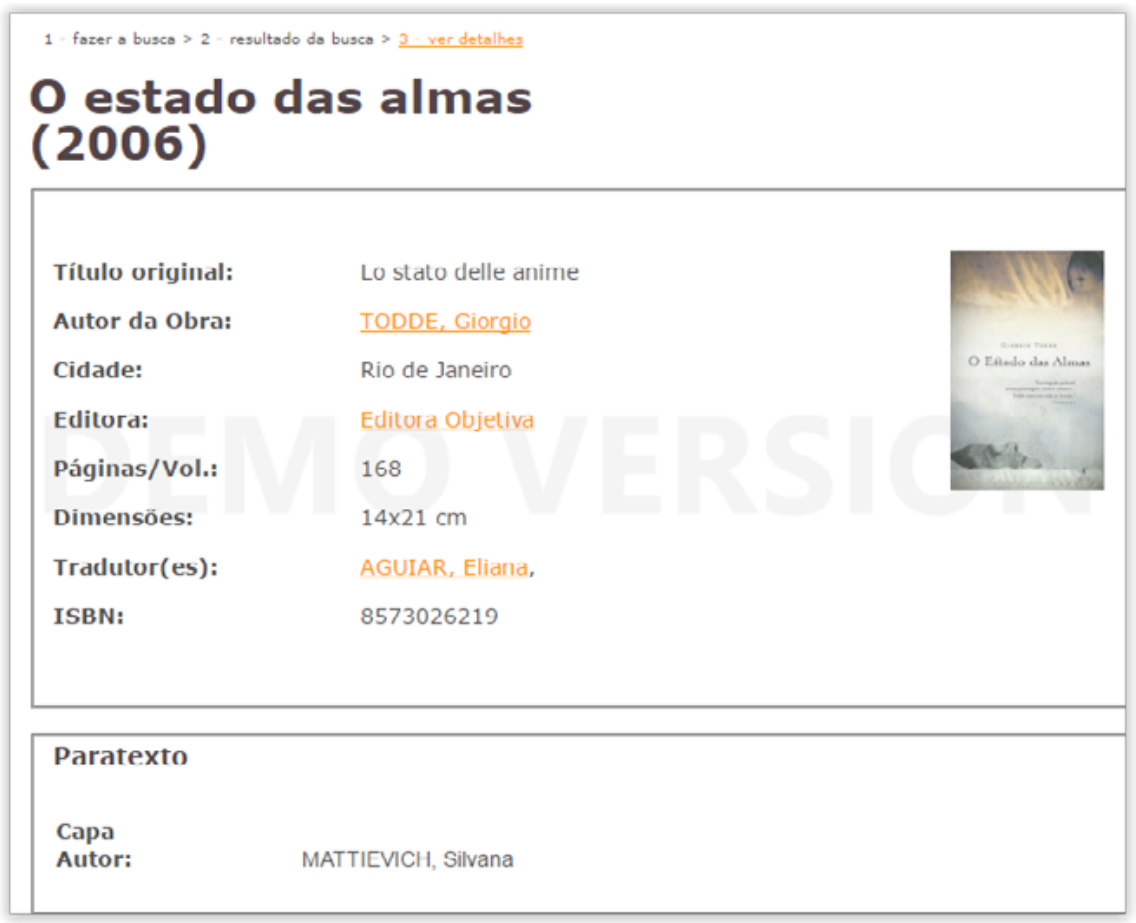

Fonte: elaborado pelos autores, 2016.

Recurso disponível em: http://www.usp.br/dlit/dicionario/busca.php.

Outro resultado, ilustrado pelas figuras 1 e 2 , representa a constituição do produto base de dados bibliográfica e a sua disponibilização para acesso público. Essa base de dados tem por nomenclatura: "Dicionário da Literatura Italiana Traduzida" - DLIT, e se propõe a servir de fonte de consulta para os pesquisadores que buscam informações relativas a obras da literatura italiana traduzidas para o português.

Em termos biblioteconômicos, o DLIT é uma base de dados bibliográficos que contempla tacitamente aspectos do processo catalográfico, resguardados os devidos contextos e objetivos já aludidos 
Entretanto, como mencionado, o DLIT apesar de ser uma base bibliográfica, não é em essência um catálogo bibliográfico, embora opere como um. É construído a partir de representações descritivas de livros impressos e possibilita estabelecer um procedimento de comunicação entre uma coleção bibliográfica e os seus usuários.

Para a comunidade da área de Letras Italianas, o Projeto possibilitou desenvolver uma análise do impacto cultural da literatura italiana sobre a cultura brasileira. O panorama identificado pelo projeto inicial, relativo à literatura traduzida de 1900 a 1950, contribuiu com a compilação de verbetes, gerou estudos variados como, por exemplo, o caso do autor "Giovanni Papini”. Esse autor, apesar de atualmente ser quase esquecido até na Itália, teve oito obras publicadas no Brasil por editoras importantes e cujo sucesso brasileiro acompanhou a sintonia entre a indústria cultural italiana e a brasileira - apesar das diferentes fases político-sociais na Itália e no Brasil.

Em relação à segunda fase materializada pelo Projeto DLIT, a observação constatada pelos pesquisadores foi a ausência, até 1956, de traduções integrais da obra "Decameron" de Giovanni Boccaccio. Na segunda parte do século XX, começa o seu intensivo resgate, apesar da extensão da obra com a publicação de um grande número de traduções parciais e integrais, as duas últimas editadas em 2013, durante a comemoração dos 700 anos do autor (WATAGHIN; PETERLE; SANTURBANO, 2016).

Como reflexo do trabalho realizado, encontram-se os temas estimulados para pesquisas futuras, na comunidade acadêmica da área da Letras Italianas como: 1) a história de editoras engajadas nas traduções da literatura italiana; 2) a posição da literatura italiana traduzida em editoras de grande peso ou especialmente prestigiosas; 3 ) as traduções que apresentam especiais dificuldades; 4) os problemas de tradução, típicos de gêneros diferentes (literatura infantil, bestsellers, outros); 5) a recepção brasileira de determinados autores; e 6) a recepção e tradução de novos títulos da literatura para a infância (WATAGHIN; PETERLE; SANTURBANO, 2016).

\section{Considerações Finais}

Na descrição do Projeto "Dicionário da Literatura Italiana Traduzida no Brasil: a partir de 1951", verifica-se a possibilidade de colaboração efetiva gerada entre as áreas de Biblioteconomia e de Letras Italianas. Evidencia-se a contribuição que um método tradicional como a catalogação pode ser aproveitada, com devidos ajustes e contextos, na construção de uma base de dados referencial da produção editorial para subsídios de áreas de pesquisa. Por outro lado, se mostram 
as demandas de informação e de pesquisas que viabilizam parcerias interdisciplinares.

Ao entender que o projeto DLIT, ao mapear as obras da literatura italiana traduzida, não só identifica e quantifica uma produção editorial, mas desenvolve um modelo de mapeamento desta produção. Modelo este que, ao mesmo tempo, resgata uma história editorial, preserva e dá acesso ao produto desta produção - o livro, para estudiosos e interessados no tema.

Os resultados do projeto realizado abrem a possibilidade de que, do outro lado do oceano, na Itália, outros estudiosos (brasilianistas e/ou italianistas, especialistas em literatura, tradução, estudos comparados) se ocupem das trajetórias e dos encontros dos textos da literatura brasileira com o público, os editores, os estudiosos, os críticos do contexto de sua acolhida italiana (WATAGHIN; PETERLE; SANTURBANO, 2016).

Embora não se tenha construído um catálogo bibliográfico strictu sensu, ressalta-se que as competências técnicas do bibliotecário podem ser aproveitadas em projetos similares, que explorem a diversidade da produção editorial no Brasil.

\section{Referências}

CÓDIGO de catalogação anglo-americano. 2 ed. rev. 2002. São Paulo: FEBAB; Imprensa Oficial do Estado de São Paulo, 2004.

EVEN-ZOHAR, I. La posizione della letteratura tradotta all'interno del polisistema letterario. In: Nergaard, S. (Org.). Teorie contemporanee della traduzione. Milano: Bompiani, 2007. p.225-238.

LEFEVERE, A. Tradução, reescrita e manipulação literária. Bauru: EDUSC, 2007.

MEY, E. S. A.; SILVEIRA, N. C. Catalogação no plural. Brasilia: Briquet de Lemos, 2009.

PETERLE, P. Possíveis percursos no babélico labirinto da literatura italiana traduzida no Brasil. In: PETERLE, P.; SANTURBANO, A.; WATAGHIN, L. (Orgs.). Literatura italiana traduzida no Brasil 1900-1950. Niterói, RJ : Comunitá, 2013. p.40-46.

PETERLE, P.; SANTURBANO, A.; WATAGHIN, L. (Org.). Literatura Italiana Traduzida no Brasil 1900-1950. Rio de Janeiro: Ed. Comunità Italiana, 2013.

RAMOS FAJARDO, C. Principios generales e instrumentos de catalogación. In: MOLINA, M. P. Catalogación de documentos: teoria y práctica. $2^{\mathrm{a}}$ ed. Madrid : Editorial Sínteses, 2001 p. 21-52.

WATAGHIN, L. A literatura italiana traduzida no Brasil. São Paulo: FFLCH/USP, 2013.

WATAGHIN, L. Para um mapeamento da recepção da literatura italiana no Brasil. In: PETERLE, P.; SANTURBANO, A.; WATAGHIN, L. (Orgs.). Literatura italiana traduzida no Brasil 1900-1950. Niterói, RJ : Comunità, 2013. p.21-39. 
WATAGHIN, L.; PETERLE, P.; SANTURBANO, A. Introdução: dicionário da literatura italiana traduzida: arquivos e coleções literárias. Dicionário Bibliográfico de Literatura Italiana Traduzida no Brasil a partir de 1951. Disponível em: < http://www.usp.br/dlit/dicionario/intro.html

Recebido em 12/12/2016

Aprovado em 10/04/2017 